\title{
The ecology of Roman trade. Reconstructing provincial connectivity with similarity measures
}

\author{
Xavier Rubio-Campillo ${ }^{\mathrm{a}, *}$, Jean-Marc Montanier ${ }^{\mathrm{b}}$, Guillem Rull ${ }^{\mathrm{c}}$, Juan Manuel Bermúdez \\ Lorenzo $^{\mathrm{d}}$, Juan Moros Díaz ${ }^{\mathrm{d}}$, Jordi Pérez González ${ }^{\mathrm{d}}$, José Remesal Rodríguez ${ }^{\mathrm{d}}$ \\ ${ }^{a}$ School of History, Classics and Archaeology, University of Edinburgh, UK \\ ${ }^{b}$ Barcelona Supercomputing Centre, Spain \\ ${ }^{c}$ SIRIS Lab, Research Division of SIRIS Academic, Spain \\ ${ }^{d}$ CEIPAC, Universitat de Barcelona, Spain
}

\begin{abstract}
The creation of the Roman Empire promoted the connectivity of a vast area around the Mediterranean sea. Mobility and trade flourished over the Roman provinces as massive amounts of goods were shipped over thousands of kilometres through sea, rivers and road networks. Several works have explored these dynamics of interaction in specific case studies but there is still no consensus on the intensity of this connectivity beyond local trade.

We argue here that the debate on the degree of large-scale connectivity across the empire is caused by a a lack of appropriate methods and proxies of economic activity. The last years have seen an improvement on the availability of evidence as a growing amount of datasets is collected and published. However, data does not equal knowledge and the methods used to analyse this evidence have not advanced at the same pace.

A new framework of connectivity analysis has been applied here to reveal the existence of distinctive trade routes through the provinces of the Western region of Rome. The amphora stamps collected over more than a thousand sites have been analysed using quantitative measures of similarity. The patterns that emerge from the analysis highlight the intense connectivity derived from factors such as the spatial closeness, presence of military units and the relevance of the Atlantic sea as a main shipping route.
\end{abstract}

Keywords: Rome, trade, amphora stamps, MRPP, Jaccard

3 is one of the most debated aspects of the

4 Roman economy. Hypotheses oscillate be-

\footnotetext{
${ }^{*}$ Corresponding author

Email address: xavier.rubio@ed.ac.uk (Xavier Rubio-Campillo)
}

tween a unified market defined by a constant flow of goods through long-range trade to isolationist approaches based on autonomous regions with little contact, with some exceptions (Temin, 2001; Bang, 2007).

Both archaeological and written sources indicate that there was a large diversity of scenarios as connectivity was not homoge- 
neous and some regions were much more 56 integrated than others. A key player of ${ }_{57}$ this integration was the Roman army as its 58 supply required the import of vast quan- 59 tities of products (Scheidel et al., 2007, 60 591). They were mostly produced in spe- 61 cialised provinces and required large-scale 62 trade. A good example of this connectivity 63 is the shipping of massive amounts of olive 64 oil from the Baetican province to Britan- 65 nia after its conquest (Remesal Rodríguez, 66 2011, 60). These basic goods were dis- 67 tributed amongst military garrisons but 68 it seems probable that the trade network 69 rapidly expanded to supply civilian settle- 70 ments (Williams and Peacock, 1983). Other 71 goods such as exotic foods were widely 72 shipped to distant urban centres using non- 73 military redistribution networks (Livarda 74 and Orengo, 2015; Orengo and Livarda, 75 2016). However, the general question re- 76 mains unanswered: how frequent and in- 77 tense were these economical contacts be- 78 yond specific case studies?

The topic has a renewed interest as 80 an increasing corpus of datasets includ- 81 ing archaeological, epigraphical and written 82 sources is becoming available. One exam- 83 ple of this exciting explosion of evidence is 84 the Orbis project which is focused on ex- 85 ploring the cost of mobility along the entire 86 Roman Empire (Scheidel, 2015). Other ini- 87 tiatives such as the Pelagios project aims at 88 aggregating tens of different databases to 89 generate a multifaceted view of the classi- 90 cal world (Barker et al., 2016). This col- 91 lection of evidence is a critical step towards 92 understanding the Roman economy but its 93 use also presents several challenges (Bow- 94 man and Wilson, 2009, 3-87). As other au- 95 thors have pointed out this data is riddled 96 with biases and uncertainty up to the point 97 where it is difficult to find patterns beyond 98 the noise (Bevan, 2014, Wilson, 2009). The datasets being merged often have diverse temporal and spatial dimensions and were collected by different formats and methods while the projects creating them use different theoretical approaches to the past (Bevan, 2015; Calvanese et al., 2016).

The aim of integrating datasets should be combined with the creation of methods able to tackle the complexities of the existing evidence (Brughmans and Poblome, 2016). Roman studies typically use descriptive statistics and linear regressions to analyse relations between variables (Wilson, 2009) but these generic approaches were not designed to face the uncertainty of archaeological data. First, our sample sizes are usually very low as they consist of tens or hundreds of data points for a vast region that did not remain stable over time. Second, the data points have a large degree of uncertainty which is badly captured by exploratory methods and require the use of probabilistic approaches to the past (Yubero-Gómez et al., 2016; Crema, 2015; Bevan et al., 2013a.b). Finally, the multiple biases generated by the archaeological process should be taken into account while analysing the existing evidence $(\overline{\mathrm{Be}}-$ van, 2012; Rubio-Campillo et al., 2012).

This work presents a method to study provincial connectivity through the estimation of similarity indexes. The premise of this analysis is that regions that share trade routes should exhibit more similar cultural traits between them than with the rest of the empire. We reconstruct here the dynamics of provincial trade based on a well-tested proxy of long-range trade: the stamps found in amphorae containers found over the entire Roman Empire (Scheidel et al., 2007, 690). By applying a NullHypothesis Significance Testing Framework 
based on ecological methods we explore two 140 specific research questions: a) was large- 141 scale trade related to the provincial struc- 142 ture? and b) can we find patterns of con- 143 nectivity between provinces beyond spatial 144 closeness?

The next two sections define the dataset 146 and the methods we used for this large-scale 147 analysis. The fourth section presents the 148 results of the analysis which are discussed 149 and interpreted in section five. The text 150 finishes with a summary of the method and ${ }_{151}$ its potential contribution within the current ${ }_{152}$ debates on the discipline.

\section{Patterns of trade in the Roman em- ${ }^{155}$ pire}

Clay amphorae are arguably the archae- 158 ological artefacts that best represent trade 159 dynamics in the classic world (Bevan, 2014). 160 These standardised containers were used 161 to transport large quantities of liquids and 162 other goods through a dense network of sea 163 and river routes. Maritime shipping was 164 the fastest and cheapest transport system so 165 amphorae were massively distributed over 166 the entire Roman empire. At the same ${ }_{167}$ time amphorae were functional and robust 168 because they were designed to be trans- 169 ported aboard ships that may be cross- 170 ing hazardous waters. This robustness and 171 widespread use has allowed amphorae to 172 survive in higher quantities and frequencies 173 than containers serving a similar purpose 174 such as wooden barrels (Tchernia, 1986). $\quad 175$

The study of these containers plays a key 176 role in our understanding of the Roman 177 economy thanks to their visibility in the 178 archaeological record (Greene, 1986, 162). 179 The production of an amphora type is typ- 180 ically linked to a specific area and prod- 181 uct so a trade link can be suggested be- 182 tween the production place of a type and the sites where the amphorae of this type are found. The aggregation of large volumes of findings reveals the degree of specialisation of certain provinces that shipped thousands of amphorae filled with a single product to distant consumption places; this dynamic can be seen in Baetica for olive oil (Remesal Rodríguez, 1998; Funari, 1996) and some areas of Italia for wine (Paterson, 1982; Loughton, 2003).

The use of this archaeological proxy also presents some challenges. Elsewhere has been argued that the information provided by amphorae findings can be potentially biased by reuse activities (Peña, 2007, pp. 61208). These biases could affect distribution patterns at least in two different aspects: a) transportation to a new destination and b) refill with a different substance than the original.

The first scenario would see an empty amphora refilled and shipped to a different location. The archaeological record does not allow us to track the route of the amphora which will always be found in the last location it was shipped. This bias would not heavily affect large-scale analysis such as the one we present here because the evidence for long-range reuse is very scarce (Peña, 2007, p. 72). If shortrange reuse was frequent then the amphorae found on nearby sites would be more homogeneous but it would not affect the role of the dataset as proxy of long-range trade.

The second scenario would break univocal ties between specific amphora types and their contents. While this bias does not affect the current work given our focus on stamps it is certainly a relevant barrier to improve our understanding of Roman trade and requires further exploration (probably through residue analysis techniques, see 
Pecci et al., 2017).

A significant percentage of these am- 227 phorae were stamped on one of their handles 228 with a code of letters and symbols. Most of 229 these codes are tria nomina identifying an 230 individual linked to trade activities, albeit 231 it is difficult to know if this person was in- 232 volved in the production of the container or 233 its contents (Remesal Rodríguez, 1998; $\mathrm{Fu}-{ }_{234}$ nari, 1996). In any case these codes high- 235 light the dynamics of trade because they 236 were not unique: amphorae found in dis- 237 tant sites were stamped with the same code 238 while containers found in the same place of- 239 ten exhibit a diversity of them. The study of 240 the frequencies of codes has found interest- 241 ing patterns on their spatiotemporal distri- 242 bution, and for this reason they seem a good 243 proxy for long-range trade in the classic 244 world (Remesal Rodríguez, 1998; Berni Mil- 245 let, 2008; Broekaert, 2015; Rubio-Campillo 246 et al., 2017).

This long tradition of amphora stamps 248 analysis has been mostly focused on sin- 249 gle sites or provinces. Here we use this 250 proxy to identify links within the Western 251 part of the Roman empire by comparing 252 the similarity of stamp codes found across 253 thousands of Roman sites. The hypothesis 254 to test can be defined as follows: sites re- 255 ceiving goods through different trade net- 256 works would be supplied by distinct pro- 257 ducers, so we should find differences in the 258 stamps found on these sites. In a majority 259 of sites only a small number of stamps has 260 been found, but if this hypothesis is cor- 261 rect then a large dataset should exhibit a 262 pattern significantly distinctive from a ran- 263 dom distribution of code stamps. In addi- 264 tion, if a group of provinces were more in- 265 tensely connected because they shared trade 266 routes then some code stamps should be 267 more present in these provinces than in the 268 rest of the areas.

The database used to test our working hypotheses is the Corpus of amphorae with Latin epigraphy compiled by the CEIPAC group over 30 years (Remesal Rodríguez et al., 2015). For each record in the dataset the following information was compiled: a) $i d$ of site where it was found, b) province where the archaeological site was located and c) stamp code. At present the Corpus contains 32.375 amphora stamps from which the amphorae collected in the city of Rome were removed for two reasons. First, the economic activities of the capital's supply were unique given its size and political role. Second, the amount of evidence collected in Rome is so large compared to the rest of the sites that the entire analysis would be biased towards this city. As a consequence the dynamics of the rest of the territory would be masked by the large weight of the capital. The remaining set of 24.092 stamps displayed 5.539 unique codes and is distributed over 1.278 sites covering a large percentage of Europe as depicted in Figure 1 .

It is worth noting that around $25 \%$ of the stamps are not complete due to fragmentation or erosion. A previous study showed that the impact of this uncertainty in large-scale analysis was low (RubioCampillo et al., 2017). As a consequence we have integrated the fragmented stamps in the dataset without further issues.

The dataset contains a wide diversity of amphora types; nevertheless a majority of stamps has been found on Dressel 20 Baetican amphorae containing olive oil and Brindisian amphorae transporting olive oil or wine. The frequency distribution of the most popular amphorae types can be seen in Figure 2.

Figure 3 shows the heterogeneity of the 


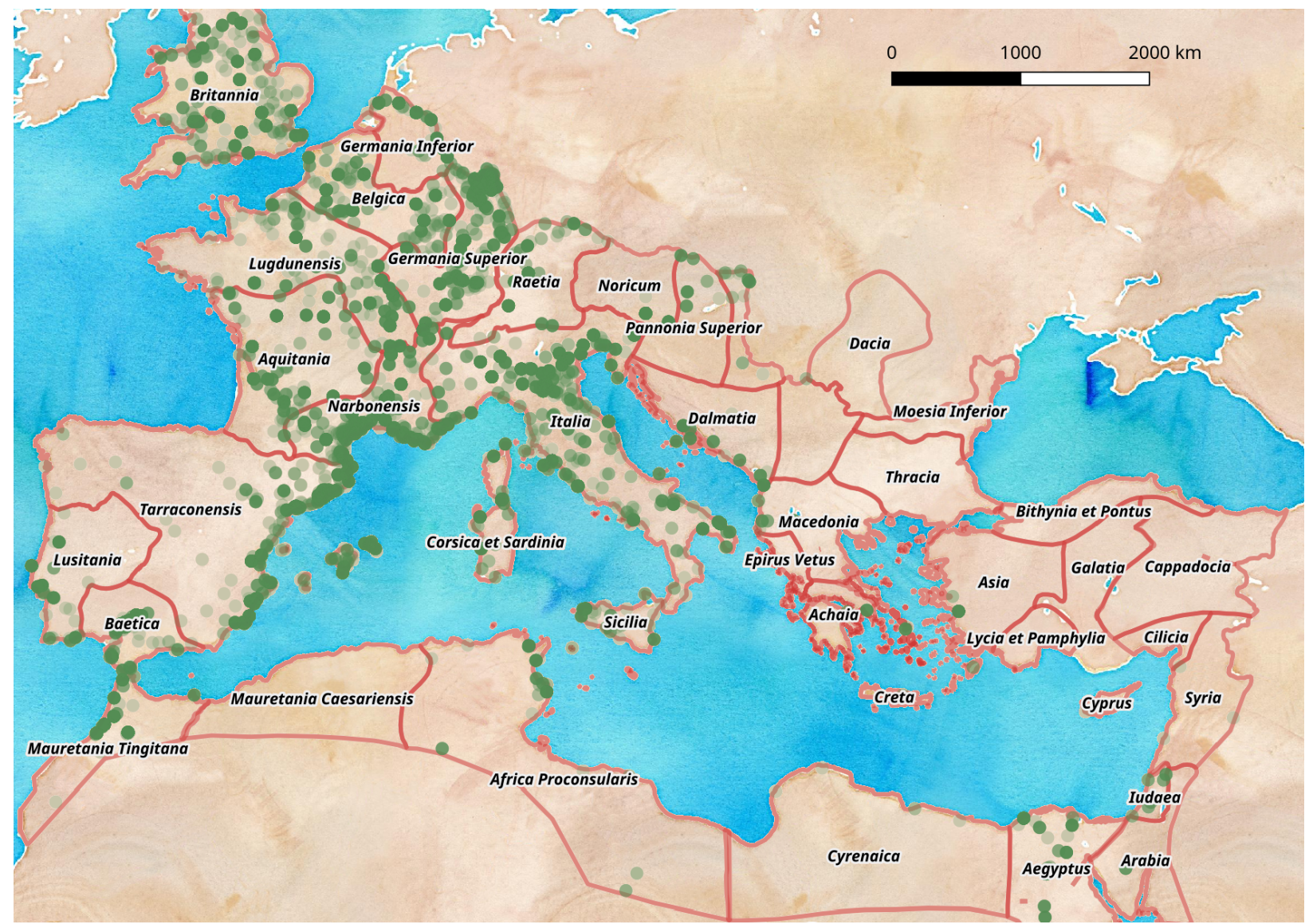

Figure 1: Spatial distribution of amphora stamps collected in the CEIPAC database. Most of the dataset comes from sites in the Western area of the Roman empire with the highest densities located at the Mediterranean coast and the provinces with strongest military presence (Britania and Germania)

sample both in terms of number of sites per 284 province and number of stamp codes per 285 site. Provinces such as Italia, Narbonensis, 286 and the two Germania have a large quantity 287 of stamps spread over several sites while in most provinces less than 100 stamps were 288 collected. The sites with a higher number of findings are located in the provinces with ${ }^{289}$ larger sample size while the sites in the rest ${ }^{290}$ of the provinces typically show less than $10^{291}$ code stamps. This pattern can be explained ${ }^{292}$ by a strong intensity bias as archaeologists ${ }^{293}$ working on some regions of Europe would have more interest in recording amphora stamps than areas where this type of stud- ${ }^{295}$ ies is less common. The challenge then is to use appropriate methods able to detect spatial patterns despite this diversity of sample sizes.

\section{Methods}

The analysis of this dataset was performed in three steps: a) creation of a dissimilarity matrix between sites b) evaluation of province significance and c) identification of province clusters.

\subsection{Jaccard distance matrix}

Dissimilarity between two sites was based on the number of stamp codes that were 


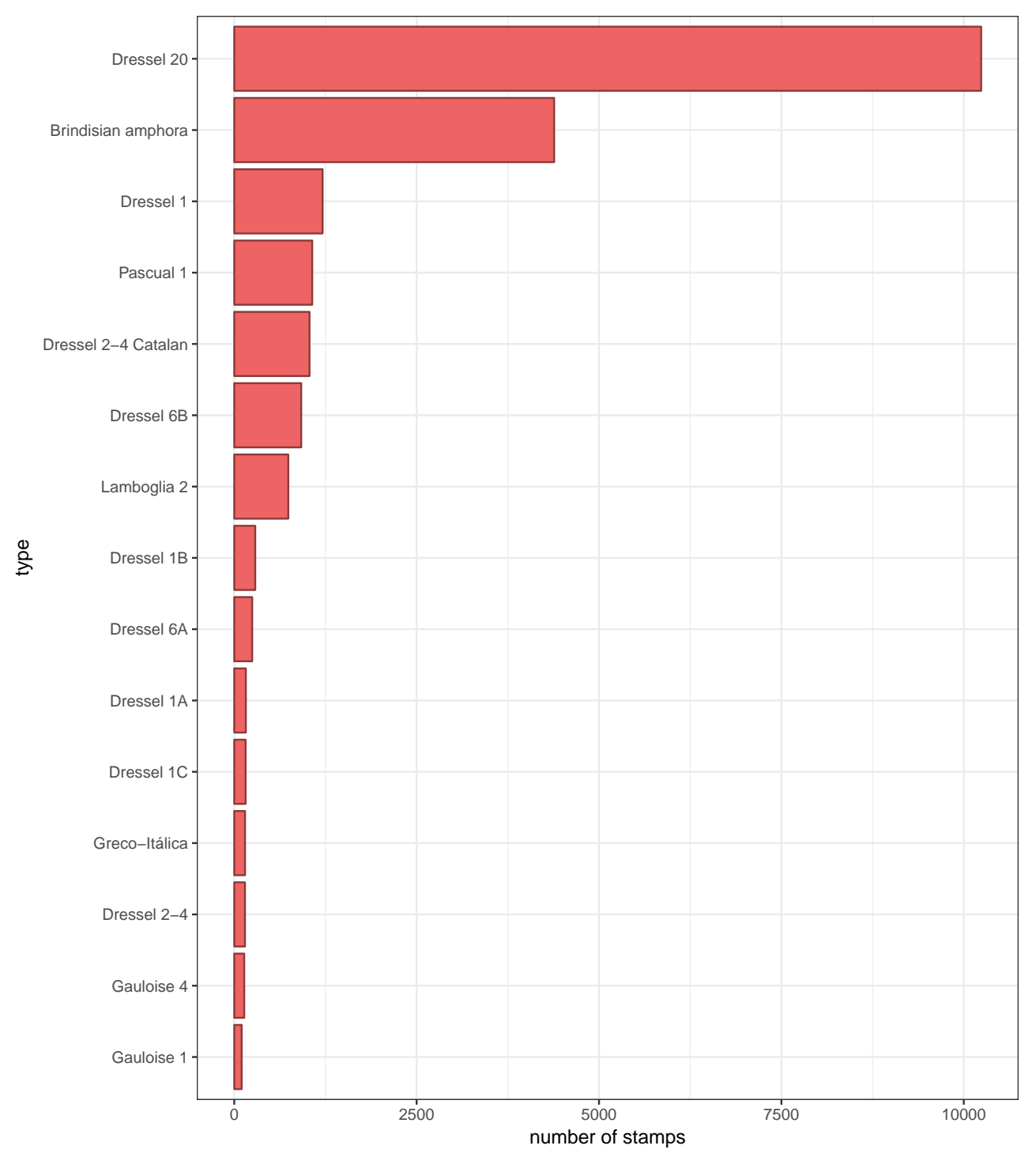

Figure 2: The CEIPAC database comprises a large diversity of containers with a total of 115 amphora types. This figure displays the frequency of the types having at least 100 stamps

present on one location and absent on the 305 other one. This was quantified with a popular similarity measure known as Jaccard 306 distance. The distance between the sets of codes $c_{i}$ and $c_{j}$ collected in a pair of sites ${ }_{307}$ $i$ and $j$ is defined as the ratio between the ${ }_{308}$ number of codes found in both sites and the ${ }_{309}$ number of codes found at least in one site ${ }_{310}$ as defined in Equation 1:

$$
D_{\text {Jaccard }}(i, j)=1-\frac{\left|c_{i} \cap c_{j}\right|}{\left|c_{i} \cup c_{j}\right|}
$$

The Jaccard distance is bounded between 0 (i.e. the sites have exactly the same stamp codes) and 1 (i.e. the sites do not share any code). The pairwise computation of this index for the entire dataset generated a squared dissimilarity matrix of 1.278 rows 


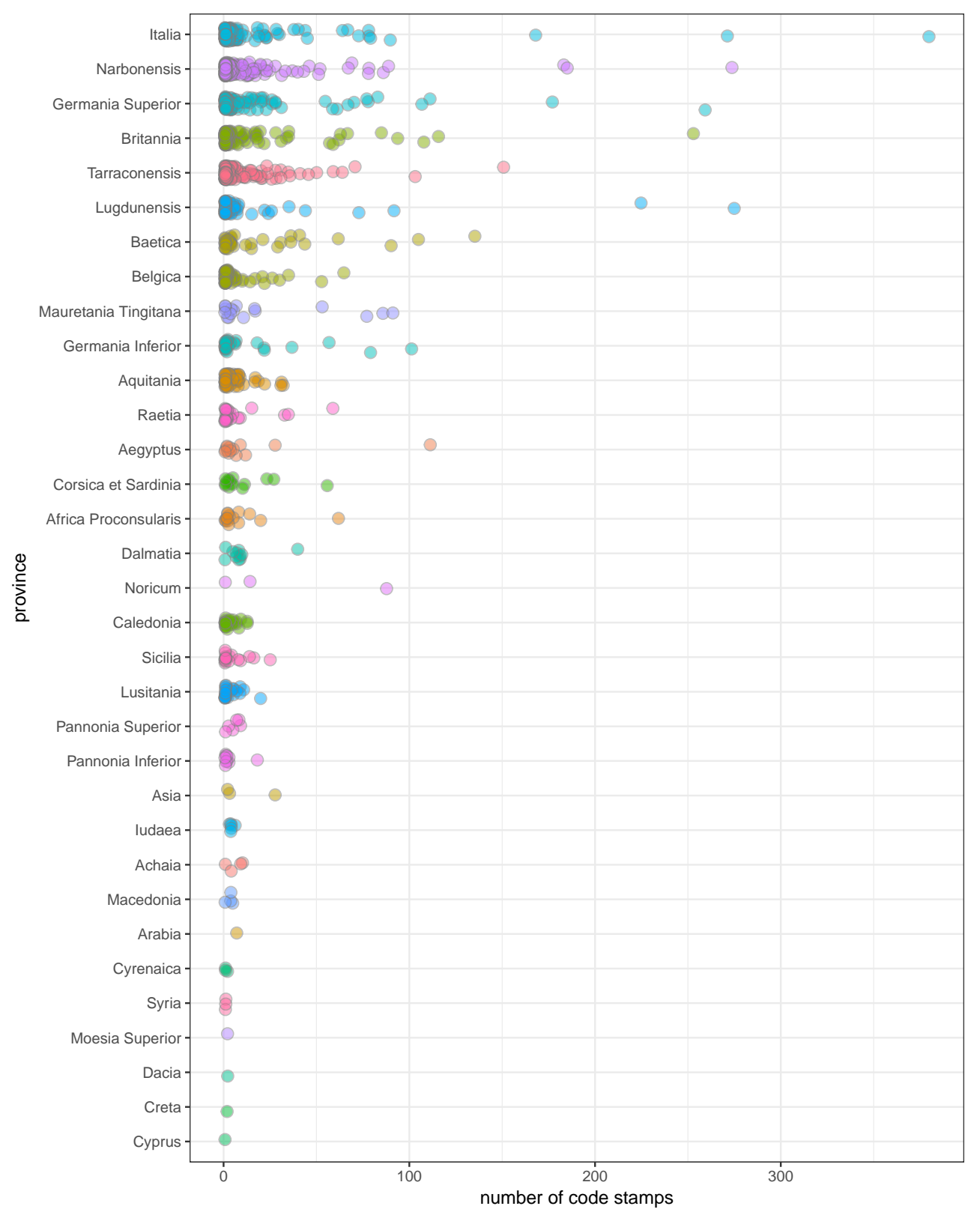

Figure 3: Distribution of sites based on its number of amphora code stamps (X axis) and province (Y axis). Each dot is a site and the provinces are sorted in decreasing order based on the total amount of stamps found on each province. Repetitions of the same stamp code on a site are counted only once

by 1.278 columns (i.e. number of sites). 317 The average distance was close to 1 as most 318 of the sites had a small number of unique ${ }_{319}$ stamps.

\subsection{Multi-Response Permutation Proce- dure}

The second step required a comparison of the Jaccard distance between sites against their province. We estimated the significance of the first hypothesis by evaluating 
the opposite null hypothesis: The Jaccard ${ }_{366}$ distance between 2 sites is independent of 367 their provincial attribution. This is equiv- 368 alent to compute the probability that two random sites from the entire dataset have a ${ }^{369}$ lower Jaccard distance than two sites ran- ${ }^{370}$ domly sampled from the same province; if ${ }^{371}$ this probability is low enough then we can ${ }^{372}$ reject the null hypothesis, thus suggesting ${ }^{373}$ that provincial structure played a role on ${ }^{374}$ trade routes.

The complex requirements of this test were met by the use of the Multi-Response Permutation Procedure (MRPP) (McCune and Grace, 2002; Mielke et al., 1976). MRPP was designed to analyse ecologi- ${ }^{376}$ cal datasets presenting similar challenges ${ }^{377}$ than the ones posed by archaeological data ${ }^{378}$ (e.g. fragmentation, noise, sampling biases). First, MRPP does not assume any specific distribution of responses unlike similar methods such as MANOVA. Second, this approach allows to give different val- ${ }^{379}$ ues to the weight of each group in the fi- ${ }^{380}$ nal result. This was relevant in our analy- ${ }^{381}$ sis because the information of each province ${ }^{382}$ was not homogeneous as the number of sites ${ }_{383}$ per province was diverse (e.g. there were ${ }_{384}$ 3 sites in Syria for 182 sites in Narbonen- 385 sis). Finally, MRPP accepted Jaccard as a 386 distance metric so no further data transfor- 387 mations were required. Despite these ad- 388 vantages to our knowledge the method has 389 only been applied once in archaeological research (Rodgers, 1987).

390

MRPP evaluates the null hypothesis by 391 comparing the average distance for the en- 392 tire dataset against the average distance for 393 elements of the same group (i.e. province) 394 weighted by its sample size. It does so by 395 performing random permutations between 396 elements and assessing changes in this dis- 397 tance.
For a set of provinces $P$ and a set of stamp codes $C_{P}$ the algorithm can be defined as follows:

1. compute the average Jaccard distance $\overline{D_{p}}$ between the sites of each province $p$ in $P$.

2. compute the weight $W_{p}$ of a province $p$ based on the ratio between its number of sites $s$ and the total number of sites in the sample:

$$
W_{p}=\frac{s \in p}{\sum_{i=1}^{P} s \in i}
$$

3. define an observed Delta value $\delta$ as the overall weighted mean of within-group means of distances:

$$
\delta=\sum_{p=1}^{P} D_{p} W_{p}
$$

4. permute the provinces associated with the different sites and compute $\delta$ again (this step is performed thousands of times).

The p-value is given by the percentage of permutations with $\delta$ lower or equal than the observed value computed in step 3 . The algorithm also quantifies an effect size $A$ suggesting the predictive power of the group (see McCune and Grace, 2002, for details).

\subsection{Clustering}

MRPP tests the statistical significance of the groups but it does not provide insights into the similarity between provinces. Our second hypothesis requires additional methods to group the provinces based on the stamp codes that can be found in their set of sites. This was achieved by creating a second matrix of mean within- and 
between-province distances from the results 430 of the MRPP. The clustering algorithm 431 neighbour joining was then used to group 432 the provinces (Saitou and Nei, 1987). This 433 algorithm was chosen because it generates 434 an unrooted binary tree from a matrix of 435 dissimilarities without making any assump- 436 tions on the existence of a root node (which ${ }_{437}$ did not exist in this case). The results could ${ }_{438}$ then be visualised using a cladogram as a 439 means to evaluate what groups were created 440 by the method.

\section{Results}

The results of these methods were organ- ${ }_{445}$ ised by the two original research questions. ${ }_{446}$

\subsection{Significance of the provincial structure ${ }_{448}$}

The application of the MRPP algorithm 449 generated the results that can be observed 450 in Table 1:

\begin{tabular}{lc} 
& value \\
\hline p-value & $<0.001$ \\
observed $\delta$ & 0.9974 \\
within-province distance & 0.9939 \\
$A$ & 0.0035 \\
\hline
\end{tabular}

Table 1: Results of MRPP using the entire sample 459

460

The observed average within-province 461 distance $\delta$ is consistently lower than the per- 462 muted $\delta$ values. As a consequence the null ${ }_{463}$ hypothesis that there is no relation between ${ }^{464}$ the province of a site and its stamps has a very low probability. However, the effect 465 size $A$ is low despite the high significance of ${ }_{466}$ the provincial structure.

The extreme diversity and sparsity of the 468 dataset causes all Jaccard distances to be ${ }_{469}$ very high due to the low number of codes 470 found in a majority of sites. Hundreds of ${ }^{471}$ sites have 5 or fewer codes so the probability that two of these locations share one code is very low, thus generating an $A$ close to 0 . This issue is summarised in Figure 4 where it is observed that the number of codes per site is not normally distributed. A majority of sites has one or two codes while the shape has a very long tail due to a small group of sites where hundreds of stamps were recorded.

This uneven distribution of codes is probably caused by excavation biases as most sites have not been fully excavated or have not published all their findings. The large number of sites with a small amount of codes is adding noise to the general picture by increasing the average Jaccard distances between sites.

This impact can be explored by repeating MRPP for filtered datasets of sites having at least a Minimum Number of Codes (MNC). An iterative process was performed with MNC values ranging from 1 to 100 (being MRPP with $M N C=1$ equivalent to the previous analysis). Results can be seen in Figure 5

The signal given by $A$ gradually intensifies as we discard sites with a low number of codes. It reaches a critical value an order of magnitude higher than the previous result when MRPP is computed on sites with at least 70 codes. The number of sites used in the analysis is rather low at this point and as a consequence $A$ decreases again for $M N C \geq 75$.

\subsection{Provincial similarity}

A given $M N C$ value was required to create the distance matrix of within- and between- province dissimilarities. The choice of $M N C$ needed to balance the effect size $A$ against the number of sites involved in the analysis; if the value of $M N C$ 


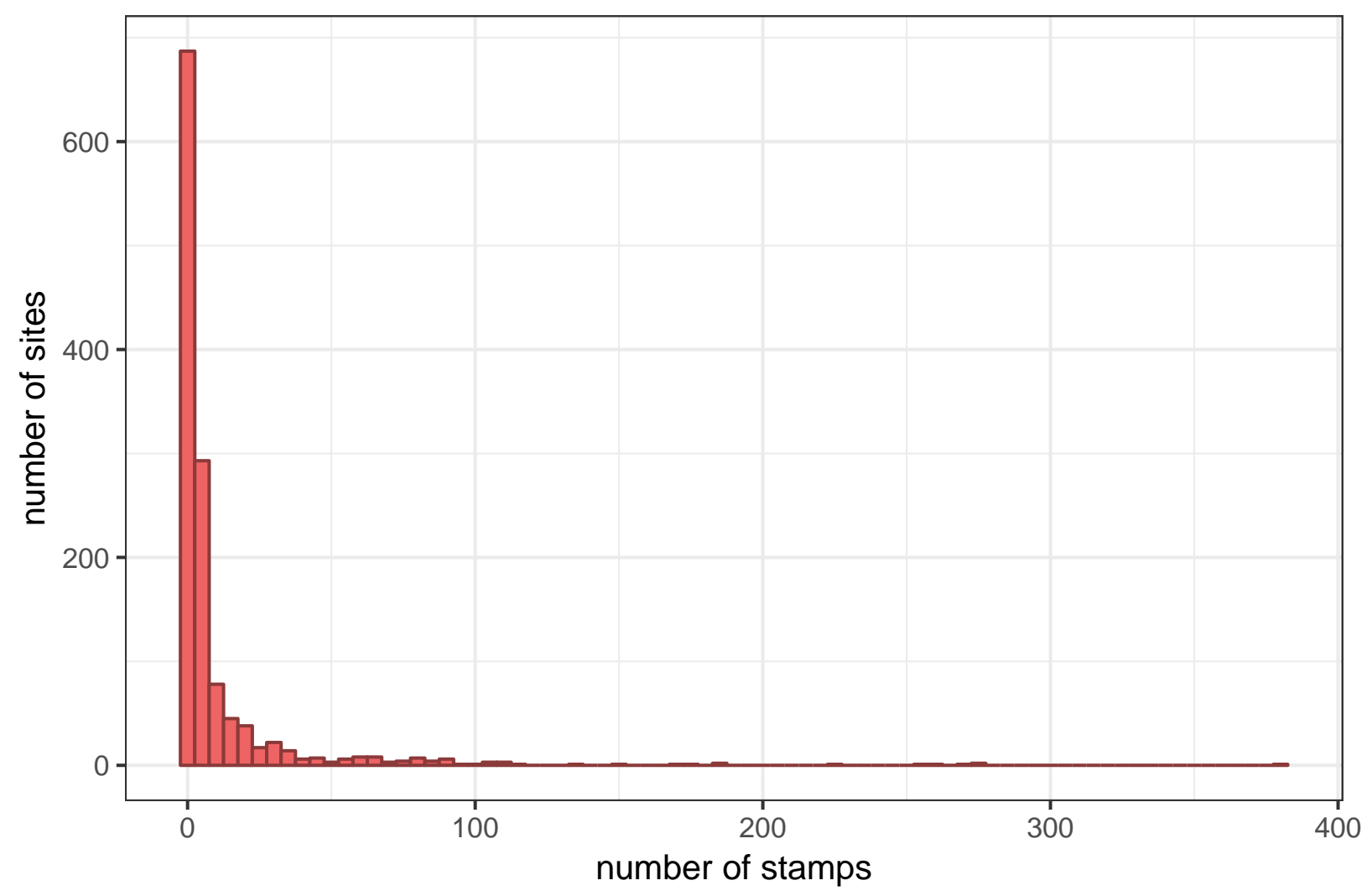

Figure 4: Histogram illustrating the number of code stamps per site with a bin width of 5 . The distribution is extremely skewed with 800 sites containing less than 5 codes and a single site with 380 stamps (Ostia Antica)

was too low then it would contain a low 488 signal-to-noise ratio while high $M N C$ val- 489 ues would limit the number of provinces 490 used in the clustering because at least 2 sites 491 per province are required. $M N C=20$ was 492 chosen as a compromise because it had a ${ }_{493}$ good effect size $A=0.016$ and a reasonable ${ }_{494}$ number of 154 sites. The resultant distance 495 matrix can be seen in Figure 6 .

The matrix was used to generate the ${ }^{497}$ cladogram seen in Figure 7. Two clus- ${ }^{498}$ ters emerge from this visualisation: a group ${ }^{499}$ of tightly linked Mediterranean provinces ${ }^{500}$ and a second group comprising the north- ${ }^{501}$ ern limes of the Empire.

Additional analysis were conducted to ex- plore the impact of parameter $M N C$ and dataset variations in the final results. Supplementary Figure 1 shows the comparison of the cladograms reconstructed for different $M N C$ values. This parameter exploration was performed from the complete dataset with $M N C=1$ to the highest $A$ value at $M N C=75$. Supplementary Figure 2 displays cladograms on two different subsets of the original dataset: a) stamps found on Dressel 20 amphorae and b) stamps found on other types of amphorae. This exploration was required to assess if the predominance of Dressel 20 in the dataset was responsible for the similarity patterns. 

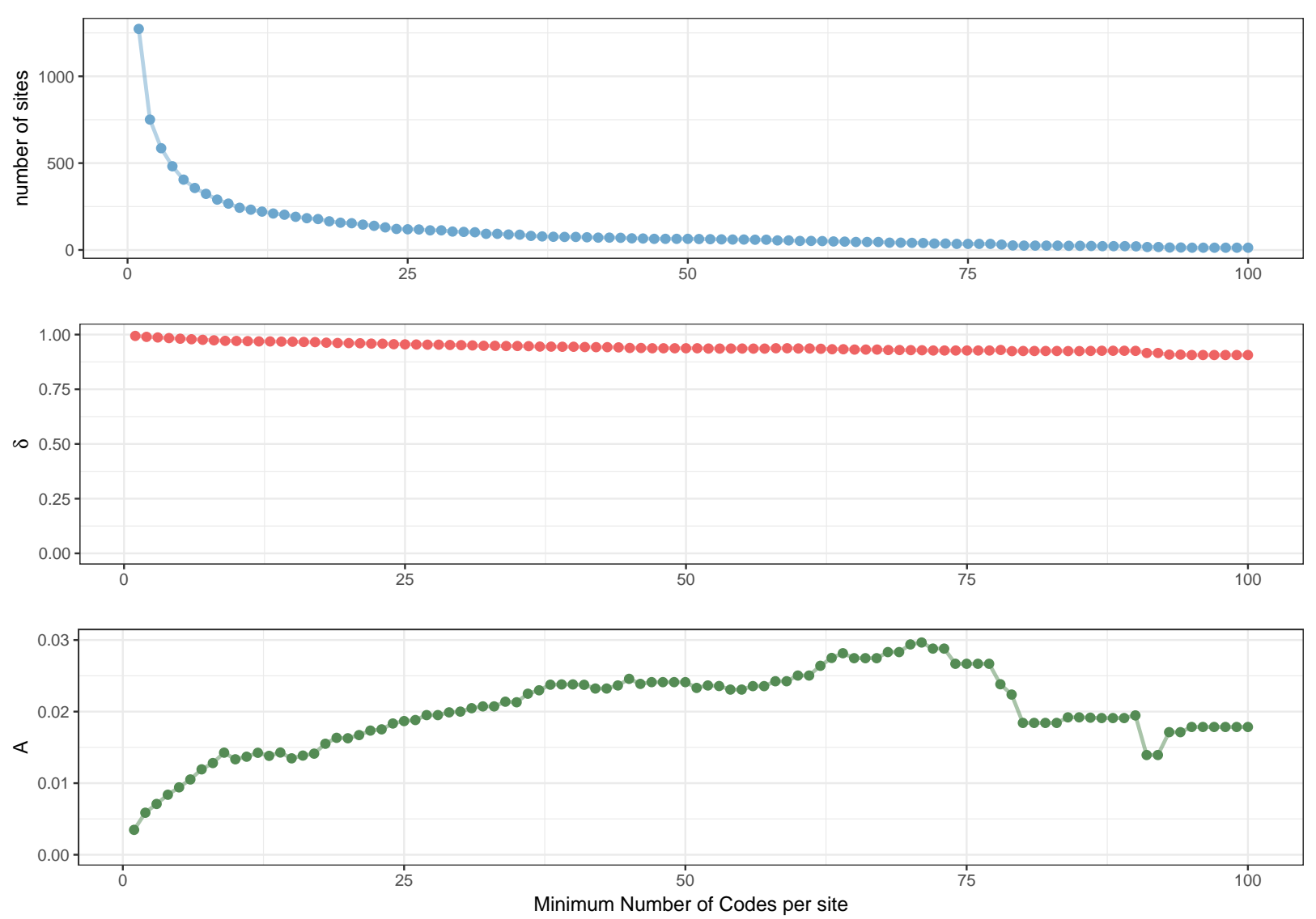

Figure 5: MRPP applied to filtered datasets. An MRPP has been performed to the collection of sites given by each MNC (X axis). The $\mathrm{Y}$ axis of the three graphs show: top) number of sites with given MNC, middle) average within-group distance or $\delta$ and bottom) effect size or $A$. The p-value for the entire dataset is consistently below 0.01

Insert Supplementary 1 here Insert 517 Supplementary 2 here

\section{Discussion}

The analysis revealed non-trivial patterns ${ }_{521}$ of distribution and these results confirm 522 that amphora stamps are good proxies of 523 long-range trade. First, provincial structure 524 played an important role on the distribu- 525 tion of liquid goods. Second, provinces that 526 were supplied through the same network ex- 527 hibit higher similarity of stamp codes. Fi- 528 nally, the approach provides insight into a 529 diversity of factors including the impact of 530 military units on logistics or the relative intensity of multiple trade routes.

The first test suggests that the stamps found in a site are related to the province where this site was located. It does not mean that trade was organised independently on every province, but it shows how distant regions of the Empire were supplied by different trade networks based on their code stamps. It is worth noting that a large percentage of the dataset is made by containers produced in specialised locations such as the Dressel 20 olive oil amphorae in the Guadalquivir river (Mattingly, D.J. 


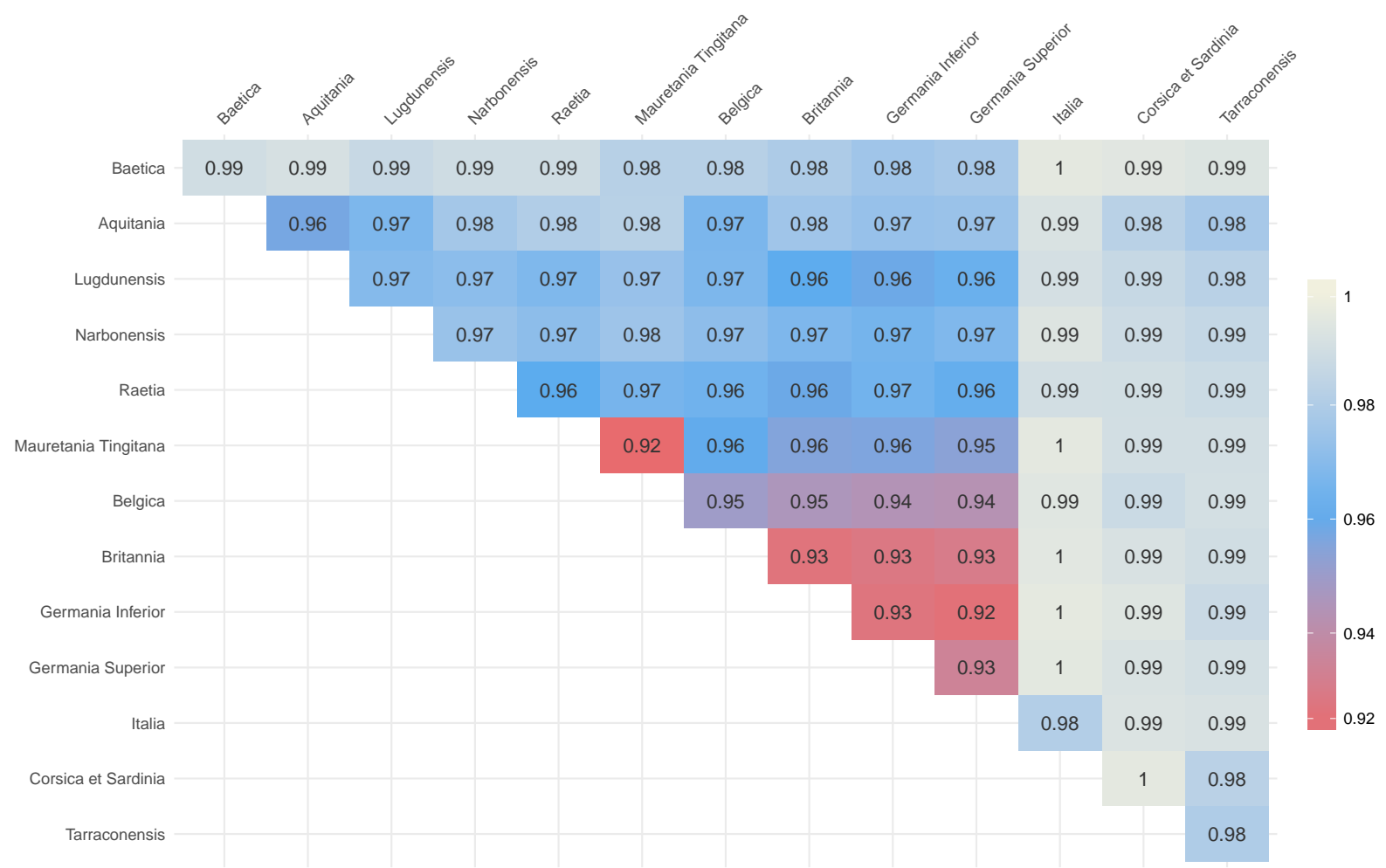

Figure 6: Distance matrix of mean within- and between- provincial distances for $M N C=20$. Provinces with higher similarity are coloured in red tones while differences close to 1 are depicted in white

1988; Remesal Rodríguez, 1998). The work- 549 shops where these amphorae were made are 550 located on a small segment of 20 kilome- 551 tres along the riverside but they regularly 552 shipped olive oil to different locations based 553 on the code that was stamped on them. The 554 patterns found on the distribution of stamps 555 can only be caused by strong links between the workshops where the amphorae were ${ }^{556}$ made and the consumption places where ${ }^{557}$ they were found; if this relation did not exist ${ }^{558}$ then the result would be a random distribu- ${ }^{559}$ tion over the Empire (so the null hypothesis ${ }^{560}$ would not be rejected).

The degree of provincial connectivity 563 found in our dataset can mostly be ex- 564 plained by geographical distance. Good ex- 565 amples of this pattern are observed in the 566 clustering of most Western Mediterranean regions (Corsica and Sardinia, Italia, Tarraconensis and Baetica) and Northern Gallia (Lugdunensis and Aquitania). It is worth noting that this spatial structure has been derived from stamp similarity and no spatial data was used as input of the analysis.

This relation between spatial closeness and stamp similarity can be explained by a combination of similar trade routes and intense local trade, including the reuse and reshipment of amphorae from local trade (Foley et al., 2012; Pecci et al., 2017). If future studies assess the relevance of amphorae reuse in Roman shipping then we will be able to improve even further our understanding of these similarities. In any case, the result appropriately captures the impor- 


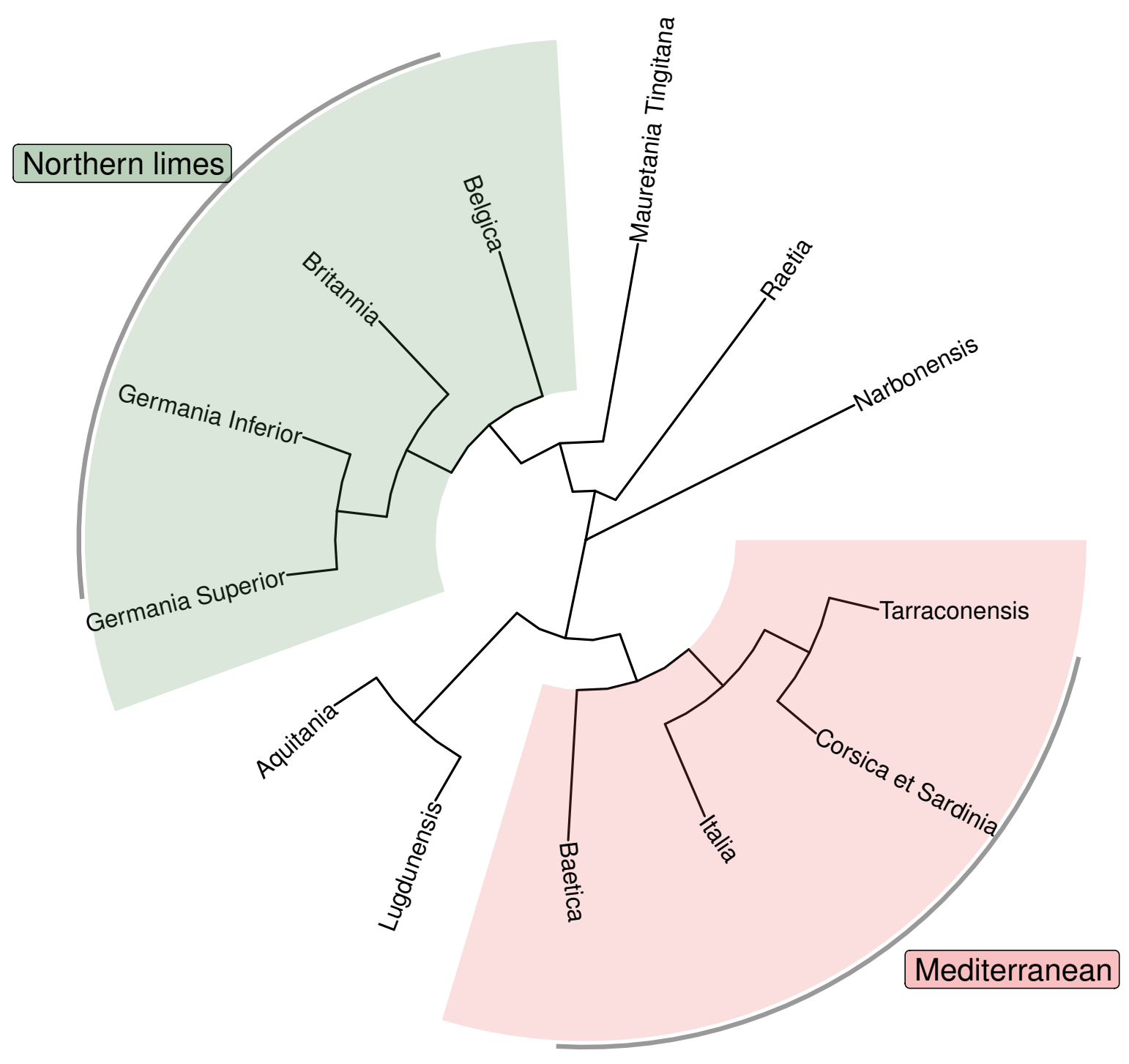

Figure 7: Similarity cladogram generated with neighbours joining algorithm for sites with $M N C=20$

tance of Tobler's First Law of Geography in 576 the case of economical dynamics: everything 577 is related to everything else, but near things 578 are more related than distant things (Tobler, 579 1970).

Spatial closeness is the main driver of con- ${ }^{581}$ nectivity but the cladogram also shows two ${ }^{582}$ interesting exceptions to this general rule. The first one is the similarity of provinces ${ }^{584}$ with strong military presence. The supply of the legions controlling the boundaries of the Roman Empire was one of the most important centres of demand for the empire (Scheidel et al., 2007, 575-576). The analysis shows the relevance of this factor as it breaks the pattern of spatial adjacency by grouping provinces with intense military activity. Germania Superior, Ger- 
mania Inferior and Britannia form the more 628 homogeneous group of the entire dataset ${ }_{629}$ which suggests that the military units de- 630 ployed there received their olive oil and 631 wine supply from the same producers (Car- 632 reras Monfort and Funari, 1998). The clus- 633 ter is directly linked to Mauretania Tin- 634 gitana; this province is thousands of kilo- 635 metres apart from the northern group but 636 it is more similar to the provinces of the 637 German limes than to any other province, ${ }_{638}$ including the entire Mediterranean. Mau- 639 retania was considered a frontier province 640 due to constant clashes between the Roman 641 army and local seminomad groups so mili- 642 tary units deployed here could have shared ${ }_{643}$ the same trade network than the legions sta- 644 tioned 3000 kilometres north (Knight, 1991; 645 Cravioto, 2002; Pons Pujol, 2009).

The second pattern breaking Tobler's 647 law is the similarity of provinces over the 648 Atlantic-Rhine route. The four provinces 649 located along the course of the Rhine river 650 (Raetia, Germania Superior and Inferior) 651 are linked to Britannia and Belgica. In contrast, Germania Superior and Germania Inferior are distant from Gallia Narbonensis which is the province where the Rhône 652 river ends its course into the Mediterranean 653 sea. This difference between the two rivers 654 suggests that the Atlantic route had more 655 intense long-range trade than the Rhine- 656 Rhône river route. This result provides ${ }_{657}$ some insight into the current debate on 658 the route network that supplied the le- 659 gions garrisoning the German limes. On 660 the one hand, several authors point out 661 that the Atlantic route was too danger- 662 ous for the ships of this period while ma- 663 jor harbour structures have been found in 664 these two rivers (Fulford, 1992; Marlière, 665 2001). On the other hand, the Atlantic ${ }_{666}$ route would have been used if ships were 667 able to safely move through the hazards of the ocean (Remesal Rodríguez, 1986, 2008, 2010). If this option was possible then the option would have been significantly cheaper in terms of cost and time (Greene, 1986, 39-41). Recent archaeological works are strengthening this hypothesis as they have discovered evidence for large-scale harbour facilities in the Atlantic facade (Carreras Monfort and Morais, 2012; Morillo et al., 2016). Our result supports this new perspective by highlighting the similarity of code stamps found in the Atlantic provinces in contrast with the low similarity between Germania and Narbonensis. This result implies that the Rhine-Rhône was not frequently used for long-range trade but other authors have highlighted the relevance of the Rhine-Rhône route for wine barrels (Marlière, 2001). This opposite results could be explained by the lack of statistical testing methods or the fact that different containers may have followed a diversity of routes.

The relevance of Baetican Dressel 20 amphorae in our dataset may also indicate that this was the main product being shipped through the Atlantic. Supplementary Figure 2 shows that this may be the case as Narbonensis is close to Germania Superior when the analysis excludes stamps found in Dressel 20. However, this result is heavily affected by sample size which forces us to discard some key provinces without the minimum number of sites (i.e. Germania Inferior). In any case, our analysis suggests that amphorae containing olive oil and wine arrived to Germania and Belgica more frequently through the Atlantic ocean than through the Rhône-Rhine route. 


\section{Concluding remarks}

The method presented here was able to 712 answer the research questions while tack- 713 ling the challenges posed by the complexity 714 of the dataset. The combination of similar- 715 ity indexes with a statistical permutation 716 test has provided valuable insights into the 717 dynamics of trade within the Roman Em- 718 pire. This result also confirms the utility of ${ }_{719}$ amphora stamps as archaeological proxies 720 of economic activity despite its high levels 721 of uncertainty. For example, the ties be- 722 tween Mauretania Tingitana and the Ger- 723 man limes was found despite the low vol- ${ }_{724}$ ume of information currently available for 725 Northern Africa (Teichner and Pons Pujol, 726 2008). This result showcases how this new ${ }_{727}$ approach is able to detect relevant signals 728 of trade amongst the noise of fragmented ${ }_{729}$ archaeological data.

Nevertheless, the approach has limita- 731 tions as any other method. First, the analy- 732 sis is effective for large-scale resolutions and 733 it would provide unreliable results in case 734 of being applied at a lower scale, due to 735 the need of large sample sizes. Addition- 736 ally, we do not have any temporal informa- 737 tion beyond amphora classifications and for 738 this reason this analysis cannot be used to 739 track change over time. This limit is de- 740 fined by the dataset; the method could be 741 extended by introducing temporal dynamics 742 based on probabilistic approaches (Yubero- 743 Gómez et al., 2016). However, the coarse 744 scale of chronologies based on amphora clas- 745 sifications would possibly decrease the sta- 746 tistical robustness of the results.

Our approach could also be potentially 748 complemented by spatial analysis for com- 749 parisons between stamp similarity and spa- 750 tial closeness. This could strengthen the 751 results but initial attempts based on Man- 752 tel tests suggested that spatial patterns were too sensitive to the uncertainty of this dataset. A quick glance to Figure 1 suggests a major impact of intensity and excavation biases over the analysed territory that would heavily affect any result obtained by pure spatial techniques.

The method presented here generates new opportunities for our understanding of the Roman economy despite these limitations. The same approach could be applied to identify differences in trade routes beyond provincial affiliation such as the existence of unique logistic networks for military or civilian sites, the use of different river routes over the territory or distinctive distributions of amphora types. The combination of similarity distances with statistical tests also opens the door to comparative analysis between the routes followed by different goods and types of containers. The use of other proxies is important because amphora is the most visible archaeological proxy for long-range trade and by its very own nature its importance can overemphasize provincial connectivity (Woolf, 1992). The analysis of goods more vulnerable to postdepositional processes such as textiles may provide a different perspective by highlighting the complexity and diversity of Roman trade (Greene, 1986, 13-15).

The last years have seen a dramatic increase in the quantity and quality of datasets on the Roman empire, but data does not automatically transform into knowledge. This work illustrates the current need for hypothesis testing in the study of past economies. Quantitative analysis is not as common in Roman archaeology as it is in other archaeological fields where statistics have been regularly applied for decades (Thomas, 1978). The study of Roman economy needs appropriate quantita- 
tive methods able to tackle the challenges 793 posed by archaeological evidence in order 794 to identify meaningful patterns in complex ${ }^{795}$ datasets (Bevan, 2015). The field needs ${ }_{797}^{796}$ to move forward from basic exploratory 798 data analysis towards the use of new frame- 799 works able to test specific working hypothe- 800 ses. This combination of new datasets and ${ }^{801}$ methods is the only way to answer the big ${ }_{803}^{802}$ questions of the field and advance in our un- 804 derstanding of the complexities of the clas- 805 sic world.

\section{Acknowledgements}

Funding for this work was provided by the ${ }_{811}$ EPNet project (European Research Coun- 812 cil Advanced Grant - 340828). GR was ${ }^{813}$ funded by the Torres Quevedo Grant PTQ- ${ }^{814}$ 15-07419. We would like to thank María ${ }_{816}^{815}$ Coto, Simon Carrignon and two anony- 817 mous reviewers for their comments on pre- 818 vious versions of the manuscript. Province ${ }^{819}$ boundaries were based on the work of An- ${ }_{821}^{820}$ cient World Mapping Center (2016). All ${ }_{822}^{821}$ analysis have been performed in $\mathrm{R}$ using ${ }_{823}$ the libraries vegan ggtree and ggplot2 ( $\mathrm{Ok}-{ }_{224}$ sanen et al., 2007: Yu et al., 2017; Wickham, ${ }^{825}$ 2009).

Source code and datasets are available ${ }_{828}^{827}$ under Open licenses and can be freely acces- 829 sible from https://github.com/xrubio/ 830 ecologyStamps.

Research was conceived by JMM, XRC ${ }_{833}^{832}$ and JRR. Dataset was collected by JMBL, ${ }_{834}^{833}$ JMD and JPG and processed by GR. JMM 835 and XRC performed the analysis. XRC 836 wrote the paper.

\section{References} man empire provinces ad 200. http: ${ }_{843}$ //awmc.unc.edu/awmc/map_data/shapefiles/ political_shading/roman_empire_ad_200_ provinces.shp accessed: 2016-11-21.

Bang, P. F., 2007. Trade and Empire In Search of Organizing Concepts for the Roman Economy. Past \& Present 195 (1), 3-54.

Barker, E., Simon, R., Isaksen, L., de Soto Cañamares, P., 2016. The pleiades gazetteer and the pelagios project. In: Berman, M., Mostern, R., Southall, H. (Eds.), Placing Names: Enriching and Integrating Gazetteers. Indiana University Press, pp. 97-109.

Berni Millet, P., 2008. Epigrafía anfórica de la Bética: nuevas perspectivas de análisis. Vol. 29 of Instrumenta. Edicions Universitat Barcelona, Barcelona.

Bevan, A., 2012. Spatial methods for analysing large-scale artefact inventories. Antiquity: a quarterly review of archaeology 86 (332), 492506.

Bevan, A., 2014. Mediterranean Containerization. Current Anthropology 55 (4), 387-418.

Bevan, A., 2015. The data deluge. Antiquity 89 (348), 1473-1484.

Bevan, A., Conolly, J., Hennig, C., Johnston, A., Quercia, A., Spencer, L., Vroom, J., 2013a. Measuring chronological uncertainty in intensive survey finds: a case study from Antikythera, Greece. Archaeometry 55 (2), 312-328.

Bevan, A., Crema, E., Li, X., Palmisano, A., 2013 b. Intensities, interactions and uncertainties: some new approaches to archaeological distributions. In: Bevan, A., Lake, M. (Eds.), Computational approaches to archaeological space. Left Coast Press, pp. 27-52.

Bowman, A., Wilson, A., 2009. Quantifying the Roman economy: methods and problems. Vol. 1. Oxford University Press.

Broekaert, W., 2015. Sticky Fingers. The Investment Structure of the Spanish Oil Business. Cahiers Mondes anciens 7.

Brughmans, T., Poblome, J., 2016. Roman bazaar or market economy? Explaining tableware distributions through computational modelling. Antiquity 90 (350), 393-408.

Calvanese, D., Liuzzo, P., Mosca, A., Remesal Rodríguez, J., Rezk, M., Rull, G., 2016. Ontology-based data integration in EPNet: Production and distribution of food during the Roman Empire. Engineering Applications of Artificial Intelligence 51, 212-229.

Carreras Monfort, C., Funari, P. P. A., 1998. 
Britannia y el Mediterráneo: estudios sobre el 895 abastecimiento de aceite bético y africano en Bri- 896 tannia. Vol. 5. Edicions Universitat Barcelona. 897

Carreras Monfort, C., Morais, R., 2012. The at- 898 lantic Roman trade during the principate: new 899 evidence from the western façade. Oxford Jour- 900 nal of Archaeology 31 (4), 419-441.

Cravioto, E. G., 2002. Tumultos y Resistencia 902 indígena en Mauretania Tingitana (siglo II). 903 Gerión. Revista de Historia Antigua 20 (1), 451- 904 485.

Crema, E. R., 2015. Time and Probabilistic Rea- 906 soning in Settlement Analysis. In: Barceló, J. A., 907 Bogdanović, I. (Eds.), Mathematics and Archae- 908 ology. CRC Press Boca Raton, pp. 314-334. 909

Foley, B. P., Hansson, M. C., Kourkoumelis, D. P., 910 Theodoulou, T. A., 2012. Aspects of ancient 911 Greek trade re-evaluated with amphora DNA ev- 912 idence. Journal of Archaeological Science 39 (2), 913 389-398.

914

Fulford, M., 1992. Territorial expansion and the 915 Roman Empire. World Archaeology 23 (3), 294- 916 305.

Funari, P. P. A., 1996. Dressel 20 inscriptions from 918 Britain and the consumption of Spanish olive oil. 919 BAR.

920

Greene, K., 1986. The archaeology of the Roman 921 economy. Univ of California Press.

922

Knight, D., 1991. The movements of the auxilia 923 from Augustus to Hadrian. Zeitschrift für Papy- 924 rologie und Epigraphik, 189-208.

925

Livarda, A., Orengo, H. A., 2015. Reconstructing 926 the Roman London flavourscape: new insights 927 into the exotic food plant trade using network 928 and spatial analyses. Journal of Archaeological 929 Science 55, 244-252.

Loughton, M. E., 2003. The distribution of repub- 931 lican amphorae in france. Oxford Journal of Ar- 932 chaeology 22 (2), 177-207.

Marlière, E., 2001. Le tonneau en Gaule romaine. 934 Gallia, 181-201.

Mattingly, D.J., 1988. Oil for export? A compari- 936 son of Libyan, Spanish and Tunisian olive oil pro- 937 duction in the Roman Empire. Journal of Roman 938 Archaeology 1, 33-56.

McCune, B., Grace, J., 2002. MRPP (Multi- 940 response Permutation Procedures) and related 941 techniques. Analysis of Ecological Communities: 942 MjM Software Design, Gleneden Beach, Oregon, 943 USA, 188-197.

944

Mielke, P. W., Berry, K. J., Johnson, E. S., 1976. 945
Multi-response permutation procedures for a priori classifications. Communications in Statistics - Theory and Methods 5 (14), 1409-1424.

Morillo, A., Fernández Ochoa, C., Salido Domínguez, J., 2016. Hispania and the Atlantic Route in Roman Times: new Approaches to Ports and Trade. Oxford Journal of Archaeology 35 (3), 267-284.

Oksanen, J., Kindt, R., Legendre, P., O'Hara, B., Stevens, M. H. H., Oksanen, M. J., Suggests, M., 2007. The vegan package. Community ecology package 10, 631-637.

Orengo, H. A., Livarda, A., 2016. The seeds of commerce: A network analysis-based approach to the Romano-British transport system. Journal of Archaeological Science 66, 21-35.

Paterson, J., 1982. 'Salvation from the Sea': Amphorae and Trade in the Roman West. Journal of Roman Studies 72, 146-157.

Pecci, A., Clarke, J., Thomas, M., Muslin, J., van der Graaff, I., Toniolo, L., Miriello, D., Crisci, G., Buonincontri, M., Di Pasquale, G., 2017. Use and reuse of amphorae. Wine residues in Dressel 2-4 amphorae from Oplontis Villa B (Torre Annunziata, Italy). Journal of Archaeological Science: Reports 12, 515-521.

Peña, J. T., 2007. Roman pottery in the archaeological record. Cambridge University Press.

Pons Pujol, L., 2009. La economía de la Mauretania Tingitana (s. I-III d. C.): aceite, vino y salazones. Vol. 34. Edicions Universitat Barcelona.

Remesal Rodríguez, J., 1986. La annona militaris y la exportación de aceite bético a Germania. Editorial Complutense.

Remesal Rodríguez, J., 2008. Provincial interdependence in the roman empire: an explanatory model of roman economy. Bar International Series 1782,155 .

Remesal Rodríguez, J., 2010. De baetica a germania, consideraciones sobre la ruta y el comercio atlántico en el imperio romano. In: Viajeros, peregrinos y aventureros en el mundo antiguo. Universitat de Barcelona, pp. 147-160.

Remesal Rodríguez, J., 1998. Baetican olive oil and the Roman economy. Journal of Roman Archaeology - Suppl. series 29, 183-200.

Remesal Rodríguez, J., 2011. La Bética en el concierto del Imperio romano. Real Academia de la Historia.

Remesal Rodríguez, J., Aguilera, A., García Sánchez, M., Martín-Arroyo, D., 
Pérez González, J., Revilla Calvo, V., 2015. 997 Centro para el Estudio de la Interdependencia 998 Provincial en la Antigüedad Clásica (CEIPAC). 999 Pyrenae.

1000

Rodgers, P., 1987. Multi-Response permutation 1001 procedures. Computer and Quantitative Meth- 1002 ods in Archaeology 7957, 45-54.

1003

Rubio-Campillo, X., Cela, J. M., Hernàndez Car-1004 dona, F. X., 2012. Simulating archaeologists? 1005 Using agent-based modelling to improve battle- 1006 field excavations. Journal of Archaeological Sci- 1007 ence 39 (2), 347-356.

1008

Rubio-Campillo, X., Coto-Sarmiento, M., Pérez, J., 1009 Remesal Rodríguez, J., 2017. Bayesian analysis 1010 and free market trade within the Roman Empire. 1011 Antiquity, in press.

1012

Saitou, N., Nei, M., 1987. The neighbor-joining 1013 method: a new method for reconstructing phy-1014 logenetic trees. Molecular biology and evolution 4 (4), 406-425.

Scheidel, W., 2015. Orbis: The Stanford Geospatial Network Model of the Roman World. SSRN Electronic Journal.

Scheidel, W., Morris, I., Saller, R. P. (Eds.), 2007. The Cambridge economic history of the GrecoRoman world. Cambridge University Press, Cambridge, UK; New York.

Tchernia, A., 1986. Le vin de l'Italie romaine. Essai d'histoire économique d'après les amphores. Vol. 261. Persée-Portail des revues scientifiques en SHS.

Teichner, F., Pons Pujol, L., 2008. Roman amphora trade across the straits of Gibraltar: an ancient Antieconomic practice? Oxford Journal of Archaeology 27 (3), 303-314.

Temin, P., 2001. A market economy in the early Roman Empire. Journal of Roman studies 91, 169-181.

Thomas, D. H., 1978. The awful truth about statistics in archaeology. American Antiquity, 231244.

Tobler, W. R., 1970. A computer movie simulating urban growth in the Detroit region. Economic geography 46 (sup1), 234-240.

Wickham, H., 2009. ggplot2: Elegant Graphics for Data Analysis. Springer-Verlag New York.

Williams, D., Peacock, D., 1983. The importation of olive oil into Iron Age and Roman Britain. In: Blázquez Martínez, J. M., Remesal Rodríguez, J. (Eds.), Producción y comercio del aceite en la antigüedad. pp. 263-280.
Wilson, A., 2009. Approaches to quantifying Roman Trade. In: Quantifying the Roman Economy. Oxford Studies in the Roman Economy, pp. 213-249.

Woolf, G., 1992. Imperialism, empire and the integration of the Roman economy. World Archaeology 23 (3), 283-293.

Yu, G., Smith, D. K., Zhu, H., Guan, Y., Lam, T. T.-Y., 2017. ggtree: an r package for visualization and annotation of phylogenetic trees with their covariates and other associated data. Methods in Ecology and Evolution 8 (1), 28-36.

Yubero-Gómez, M., Rubio-Campillo, X., LópezCachero, J., 2016. The study of spatiotemporal patterns integrating temporal uncertainty in late prehistoric settlements in northeastern Spain. Archaeological and Anthropological Sciences 8 (3), 477-490. 